\title{
Bryophytes and heavy metals: a review
}

\author{
Jelena D. Stanković, Aneta D. Sabovljević, Marko S. Sabovljević \\ Institute of Botany and Botanical Garden, Faculty of Biology, University of Belgrade, Takovska 43, 11000 Belgrade, Serbia
}

\begin{abstract}
Bryophytes, a group of terrestrial plants widely used in biomonitoring, are reviewed for their relation to heavy metals. In the present article, we summarized the knowledge on heavy metals pollution and accumulation effects on bryophytes. Mechanisms of tolerance and resistance are given as well.
\end{abstract}

Key words: liverworts, metals, mosses, relationship, toxicity

\section{Introduction}

Heavy metals naturally occur in Earth's crust, from which they are released into the atmosphere and the water bodies (Nagajyoti et al. 2010). Some of them are essential for the normal metabolic functioning of organisms, but if deficient, or present in excess, they can lead to physiological stress and have detrimental consequences (Nagajyoti et al. 2010, Krzesłowska 2011). Others, like $\mathrm{Pb}, \mathrm{Cd}, \mathrm{Al}$, and $\mathrm{Hg}$ are harmful at all concentrations (Krzesłowska 2011). Although men have used heavy metals for thousands of years (Järup 2003), reckless human behaviour, associated with urbanization and industrial development, drastically altered the previous distribution and geochemical cycles of heavy metal (Singh et al. 2011). As a consequence, numerous potentially hazardous metals were introduced into the environment or their concentrations increased substantially in areas in which they were previously present only in small quantities (Nagajyoti et al. 2010, Varela et al. 2013). Heavy metals are particularly significant as pollutants. Once introduced into the environment, they are hard to remove and tend to accumulate in the tissues of plants and other organisms through the food chains (Lee and Von Lehmden, 1973, Maevskaya et al. 2001). The steadily increasing contamination requires continuous monitoring of heavy metal concentrations in the environment and their influence and effects on ecosystems (Markert and Weckert 1989). Due to their widespread distribution and the ability to accumulate great amounts of heavy metals, bryophytes have been used as an important biological monitoring system for heavy metal pollution since 1968 (Tremper et al. 2004). Also, the phenomenon that some bryophytes tend to grow on substrates containing certain heavy metals led to their use as bioindicators that could im- ply the presence of a specific metal in that particular environment (Shaw 1987). Additionally, the relative simplicity of these plants (Markert and Weckert 1989, Reski 1998) makes them an important model for the investigation of morphological and genomic alterations in plants due to heavy metal toxicity (Carginale et al. 2004, Choudhury and Panda 2005). Finally, the key phylogenetic position of bryophytes in plant evolution, connecting the terrestrial and aquatic mode of life (Shaw and Renzaglia 2004, Shaw et al. 2011, Strotbek et al. 2013), and the fact that they are the most conservative group of land plants (Reski 1998), emphasize their importance for the studies of the evolution of plant resistance mechanisms to this type of environmental pollution.

\section{Classification of heavy metals}

Although there have been a lot of research works regarding heavy metals and their effects on the environment, there is still no broad consensus on which factors define an element as a heavy metal. One of the most accepted definitions is that heavy metals are metals with a specific density of more than $5 \mathrm{~g} \mathrm{~cm}^{-3}$ (Järup 2003). The problem with this definition is that it includes the alkali metals, alkaline earth metals, lanthanides and the actinides that in the chemical sense are not considered "heavy", while it excludes some other elements, such as arsenic, that is usually considered a heavy metal because of its chemical-ecological effects (Martin and Coughtrey 1982, Agarwal 2009). One of the classifications that can combine these properties and also account for the similarities in the heavy metal toxicity mechanisms among different organisms is based on the equilibrium constants

* Corresponding author, e-mail: marko@bio.bg.ac.rs 
that describe the formation of the metal ion-ligand complexes. According to this, there are three categories of metals with different binding preferences. Elements with an affinity for ligands containing oxygen comprise class A, elements with preferences for ligands containing nitrogen or sulphur are in class $\mathrm{B}$, while elements that have an intermediate character with the similar preference for bonding to $\mathrm{O}-, \mathrm{S}-$, or $\mathrm{N}$ containing ligands are referred to as borderline (Nieboer and Richardson 1980). The elementusually considered as heavy metals in terms of their effects on the environment are all in the class B and the borderline group (Martin and Coughtrey 1982, Choudhury and Panda 2005). Metals in the borderline group (As, $\mathrm{Cd}, \mathrm{Co}, \mathrm{Cr}, \mathrm{Cu}, \mathrm{Ni}, \mathrm{Sn}$ and $\mathrm{Zn}$ ) are less toxic than those in group B, and some of them, like copper and zinc, are even essential micronutrients in plant physiology (Choudhury and Panda 2005). They can be cofactors and activators of enzymes, take part in redox reactions and electron transfer or have structural functions in nucleic acid metabolism (Nagajyoti et al. 2010). Conversely, metals in the B group (e.g. $\mathrm{Au}, \mathrm{Ag}, \mathrm{Hg}, \mathrm{Pb}$ ), are toxic to plants at all concentrations, they are not a part of any enzyme and their effect is more pronounced with an increase in class B character.

\section{Biomonitoring of heavy metal pollution using bryophytes}

Monitoring of heavy metal pollution in the environment is a very complex process, particularly when it comes to airborne pollutants. Based on the known point sources it is possible to postulate some general theoretical principles of pollutant dispersion, but it is virtually impossible to make an exact estimation due to the complexity of the microclimate and the topography around each sampling site. Dispersion simulations are particularly hard to devise in complex surveys of airborne pollution that include a large number of sampling sites (Little and Martin 1974). Conversely, field receptor measurements that include sophisticated sampling techniques and instrumentation can indicate the presence of additional sources of heavy metals, give a precise and reliable estimation of their distribution and validate the dispersion models (Wolterbeek 2002). However, these measurements are associated with high expenses for equipment and manpower, and usually are extremely time-consuming, because they involve long-term sampling at a large number of sampling sites (Little and Martin 1974, Wolterbeek 2002). Additionally, this approach does not reveal the amounts of metals that are accumulated by the vegetation in the monitored area, or their effects on these biological systems (Wolterbeek, 2002). Thus, the use of biological systems capable of absorbing heavy metals in such a way that their tissue loads reflect the concentrations in the environment (Fernández et al. 2013) and their distance from the sources could give quantitative information about heavy metal pollution in the environment and account for its effects on the biosphere (Onianwa 2001, Chakrabortty and Paratkar 2006). In this sense, bryophytes, especially mosses, are very important (Markert and Weckert 1989, Boquete et al. 2014). Bryophytes were the first green plants to colonize the terrestrial environment (Nickrent et al. 2000), and as such had to evolve mechanisms to cope with the much greater amounts of heavy metals present on land than in the water (Degola et al. 2014). These mechanisms resulted in the ability of many bryophytes to be consistent colonizers of metal contaminated environments (Shaw et al. 1989), or to accumulate large amounts of heavy metals, in extremely polluted areas without any visible negative effect on their growth and development (Sassmann et al. 2010). This is one of the prerequisites for their use as biomonitors (Zechmeister et al. 2007). Bryophytes are usually divided into three large phyla: the liverworts (Marchantiophyta), mosses (Bryophyta), and hornworts (Anthocerophyta) (Shaw et al. 2011). Due to their morpho-physiological properties, mosses (Berg and Steinnes 1997, Zechmeister et al. 2007, Zvereva and Kozlov 2011), and recently, liverworts too (Carginale et al. 2004, Tipping et al. 2008), have been widely used as excellent systems for the monitoring of heavy metal pollution in both terrestrial and aquatic environments. The absence of a root system indicates the ability of these plants to absorb heavy metals over the entire surface (Berg and Steinnes 1997, Degola et al. 2014). The lack of the cuticle layer, which makes their cell walls easy accessible for metal ions (Choudhury and Panda 2005, Koz and Cevik 2014), pronounced ion-exchange properties (Little and Martin 1974) and a large surface-to-weight ratio also significantly contribute to this ability (Sun et al. 2009). Consequently, they can react to and reflect the changes in the heavy metal concentrations faster than most vascular plants (Zvereva and Kozlov 2011). On the other hand, due to the absence of specialized conducting tissues (Onianwa 2001) and the slow growth rate (Chakrabortty and Paratkar 2006), moss growth segments can give the information about the integrated exposure to heavy metals over longer periods of time, and not just about the current state, which is particularly important in the areas where levels of introduced heavy metals change rapidly. Advantages of bryophyte-performed monitoring, compared to conventional measurements, are cost-effectiveness and easier sampling that results in much higher sampling density and a larger number of sites that can be included in the survey (Berg and Steinnes 1997, Schröder et al. 2010). Due to the great capacity of bryophytes to absorb and retain heavy metals in high concentrations, it is also easier to perform chemical analysis and there are fewer contamination problems (Berg et al. 1995, Berg and Steinnes 1997). They also provide information on the interactions between different heavy metals and their effects on living systems, which cannot be obtained using instrumental measurements (Tremper et al. 2004). Due to all these traits, bryophytes have been successfully used for decades, not only in monitoring studies of the airborne metal pollution, where they are of immense importance (Zechmeister et al. 2003), but also in the monitoring of heavy metal pollution in aquatic environments (Kelly et al. 1987). However, these surveys do not give the absolute concentrations of elements that accumulate in the environment during a particular period (Berg et al. 1995, Berg and Steinnes 1997). To obtain that information, it is essential to establish and maintain the linear correlation between the concentrations in bryophyte tissue and the concentrations of metals to which it is exposed, accounting for 
all the factors that could disturb this relationship (Boquete et al. 2014). In this sense, the toxicity of heavy metals could also cause the alternation of the metal accumulation characteristics of the bryophytes, which could affect their reliability as biomonitoring systems (Wolterbeek 2002) or result in an effective physiological markers of heavy metal pollution (Sun et al. 2009). Investigations on bryophytes' relation with heavy metals in strictly controlled condition like in vitro culture are still in very short supply (e.g. Vukojević et al. 2004, Sabovljević et al. 2014).

\section{The accumulation of heavy metals by bryophytes}

Bryophytes accumulate heavy metals by several mechanisms, but the initial and frequently limiting step is reversible adsorption on the cell surface (González and Pokrovsky 2014). Adsorbed metals can be trapped as particulate matter within the surface layer, dissolved in liquids or deposits surrounding cells (intercellular fraction), bound in exchangeable form to exchange or chelating sites on the cell wall and outer surface of the plasma membrane (extracellular fraction) or transported inside the cells and held in soluble or insoluble form (intracellular fraction) (Vazquez et al. 1999, Salemaa et al. 2004, Castello 2007, González and Pokrovsky 2014). The extracellular accumulation of heavy metals is mediated by the ion exchange process (Wells and Brown 1990) and the formation of complexes between the metals and the organic functional groups in the cell walls of bryophytes (Shakya et al. 2008). The great binding capacities of mosses for some heavy metals are often attributed to the functional groups of polygalacturonic acid and related polymers in the cell walls (Tipping et al. 2008). Experiments exploring the acid-base properties of the mosses resulted in the detection of several possible functional groups involved in the binding of heavy metals. These include phosphodiester, carboxyl, phosphoryl and amine groups, as well as polyphenols. Considering the organic composition of the cell walls of mosses, carboxyl and phosphoryl groups could be regarded the dominant metal-binding groups forming the complexes with heavy metals at the surface of moss cells. Other groups, such as sulfhydryl and amine, could be determinants in the presence of small amounts of heavy metals or under extreme $\mathrm{pH}$ conditions (González and Pokrovsky 2014). Greater amounts of uronic acids (containing carboxyl groups) in the cell walls compared to cellulose and hemicellulose (having hydroxyl groups) could explain the higher heavy metal binding affinity of the plants cultured in the laboratory than that of the field-grown mosses observed by Wells and Brown (1987). The dominance of carboxyl and phosphoryl groups in the cell walls of different mosses could also explain the similar patterns of heavy metal adsorption in different bryophyte species seen in some studies (Vazquez et al. 1999, Tremper et al. 2004, González and Pokrovsky 2014). However, it has been observed that adsorbing properties and uptake efficiencies for the same metals may vary significantly between the mosses and liverworts (Shakya et al. 2008). This could be a result of the different cell wall composition of these two bryophyte groups, where uronic acid is a char- acteristic component of the cell wall of mosses and mannuronic acid in that of the liverworts. Other studies, performed by Rühling and Tyler (1970) and Vazquez et al. (1999), have shown that different heavy metals may follow the same order in maximum concentrations reached in the extracellular fractions regardless of the moss species, suggesting that this property depends mainly on the type of the metal. On the other hand, the affinity of extracellular binding sites for different metals may vary significantly among the species (Vazquez et al. 1999). Heavy metals adsorbed on the moss surface can reach the interior of the cell by specific membrane transport proteins or via channels present in the cell membrane (Basile et al. 2012). While the extracellular fraction of heavy metals in mosses is usually easily exchangeable and tends to reflect the current environmental conditions and sporadic peaks in contamination, the intracellular fraction is usually a result of the integration of metals during the longer period of time and thus represents the average situation in the environment (Fernández et al. 2006). It has been shown, as in other organisms, that the intracellular metal ion uptake by bryophytes displays saturation kinetics (Wells and Brown, 1990, Basile et al. 2012). Though it is hypothesised that uptake is a slow metabolically-controlled process (Vazquez et al. 1999), the study of Fernandez et al. (2006) revealed that when the bioavailability of heavy metals in the environment is high, intracellular uptake can be rather quick, leading to an accumulation of large amounts of the metals inside the cell in a short period of time. Nevertheless, in this study, the high velocity of heavy metal accumulation inside the cells of the aquatic moss Fontinalis antipyretica Hedw. resulted in a quick onset of the release of the same elements into the exterior, suggesting the existence of saturating concentrations inside cells (Fernández et al. 2006). Interestingly, in the study of Basile et al. (2012) on different mosses, intracellular concentrations of heavy metals that act as micronutrients, such as $\mathrm{Cu}$ and $\mathrm{Zn}$, remained rather constant regardless of their extracellular concentrations, while the accumulation of the elements with no metabolic function, such as $\mathrm{Pb}$ and $\mathrm{Cd}$, increased with increasing metal supply in the environment. A similar relationship between the extracellular and intracellular concentrations of Cd was also observed in the moss Pseudoscleropodium purum (Hedw.) M. Fleisch. by Fernández et al. (2013). One of the potential reasons for the lack of control of non-essential metals input could be the absence of the specific transporters for these metals (Pérez-Llamazares et al. 2011). Instead, they could be using channels and transporters of the plasma membrane that normally function in the uptake of essential ions (Wells et al. 1995, Choudhury and Panda 2005), which leads to the increase of their intracellular concentration independently of the previously existent intracellular concentration (Choudhury and Panda 2005).

\section{Sources and factors influencing the accumulation of heavy metals by bryophytes}

There are numerous sources and factors that can influence the contents of heavy metals in bryophytes (Berg et al. 
1995, Berg and Steinnes 1997, Schröder et al. 2010). Metals from the atmosphere can reach the surface of terrestrial bryophytes in solution (precipitation) or in the form of dry deposition that can later be solubilised or washed away (Couto et al. 2004, Fernández et al. 2013). Even though terrestrial bryophytes take most of the substances from the atmosphere, soil contributes significantly to the heavy metal contents (Berg and Steinnes 1997). This is particularly accentuaed during the rainy seasons or snowmelt when many substances from soil can be transported in the form of solutes, wetting the plant (Salemaa et al. 2004, Klos et al. 2012). The bioavailability and mobility of heavy metals in soil are strongly correlated to its acidity, the amount of organic matter, and the chemical composition (Salemaa et al. 2004, Klos et al. 2012). Windblown particles from the ground containing heavy metals can also influence the amounts of heavy metals in bryophytes (Berg et al. 1995, Berg and Steinnes 1997, Salemaa et al. 2004, Chakrabortty and Paratkar 2006). The retention of these particles on moss surface depends on the particle size and the surface structure (Chakrabortty and Paratkar 2006). The study of Klos et al. (2012) has shown that the contribution of each of the two mechanisms of metal transport from soil to bryophyte depends mainly on the local climatic conditions. Besides these, other sources, such as natural trace element cycling processes and leaching of the heavy metals that were previously accumulated in vascular plants through their root system, may also contribute to the heavy metal content in bryophytes (Berg et al. 1995).

Water also has a significant role in the heavy metal uptake by bryophytes. For the aquatic bryophytes, it is their living environment and the primary source of all the minerals, including the heavy metals (Claveri et al. 1994). In the case of terrestrial bryophytes, water can bring or dissolve particles that are already deposited on the bryophyte surface facilitating the uptake of heavy metals by the plant, but it can also wash out the deposited pollutants and lower down the uptake of these elements (Fernández et al. 2013). The quantity, intensity, and the duration of the precipitation determine the amount of accumulated and leached heavy metals from the terrestrial bryophytes (Chakrabortty and Paratkar 2006). The study of Čeburnis and Valiulis (1999) on two moss species (Hylocomium splendens (Hedw.) Schimp. and Pleurozium schreberi (Brid.) Mitt.) has shown that the heavier the rain, the less efficient is the uptake process for different heavy metals. They have also found that leaching can significantly influence the uptake of almost all investigated heavy metals. While the uptake efficiencies for metals such as $\mathrm{Pb}$ and $\mathrm{Ni}$ remain generally stable, leaching process may influence the uptake efficiencies for metals such as $\mathrm{Cd}, \mathrm{Cu}$ and $\mathrm{Zn}$ or even be a dominant factor in the case of Mn and Cr. However, Maevskaya et al. (2001) and Couto et al. (2004) have shown using different bryophyte species that elements that are already accumulated in intracellular or extracellular particulate fractions cannot be easily leached under normal conditions.

The chemical composition of the medium in contact with the bryophyte surface dominantly influences which heavy metal and what amount of it is going to be absorbed and retained by the plant. Different heavy metals differ in their affinities for the binding sites of the cell walls of bryophytes (Rühling and Tyler 1970), indicating that competition effects may significantly alter the uptake kinetics of a specific heavy metal (Wolterbeek 2002). The phenomenon of cation exchange capacity (CEC) is widely known to be extraordinarily high in peat-mosses (Sphagnum) so that they can acidify their environment by exchanging tissue-bound protons for basic cations. However, Sphagnum CEC seems to be similar to that of other bryophyte species (Soudzilovskaia et al. 2010). Wells and Brown $(1987,1990)$ and Wells et al. (1995) showed that different cations, depending on their binding affinity and the amounts in the environment, could exclude or prevent the binding of heavy metals to cation exchange sites in cell walls or membranes of different bryophytes (Couto et al. 2004). These findings are in agreement with the hypothesis that different sea-salt cations in the marine areas could also interfere with the uptake and retention of heavy metals (Berg and Steinnes 1997, Wolterbeek 2002). However, the concentrations of metals in the environment are usually not high enough to cause the occupation of the majority of the extracellular exchange sites. Conversely, the concentration of protons in strongly acidic environments is high enough, and may prevent the binding of different heavy metals by bryophytes or even lead to the leaching of different heavy metals from their cell wall (Couto et al. 2004). Wells and Brown (1990) have shown that in the moss Rhytidiadelphus squarrosus (Hedw.) Warnst. lowering of $\mathrm{pH}$ not only reduces the extracellular binding of $\mathrm{Cd}$ but it also affects its intracellular uptake. While the first could be due to the protonation and occupation of the available extracellular anionic binding sites, the second could be a result of the protoninduced conformational changes of transporting proteins in the bryophyte membranes. Thus, the type (soil, air, or water) and chemical composition of the media, and its acidity are probably the most important factors determining which metal and what amount of it is going to be accumulated by different bryophyte species.

\section{The effects of heavy metals on bryophytes}

Though growth and development are commonly used parameters for the assessment of the heavy metal toxicity in plants, negative effects of heavy metal pollution could be detected before the alteration of these two parameters become obvious (Wolterbeek 2002). These effects include ultrastructural changes as well as the changes in the plant physiological processes and characteristics (Sun et al. 2009, Canivet et al. 2015). Ultrastructural changes seen in bryophytes under heavy metal stress may include alternations of the chloroplast shape and thylakoid organization (Choudhury and Panda, 2005) as well as the appearance of the stromal plastoglobules in them (Basile et al. 2009). In the moss Scorpiurum circinatum (Brid.) Fleisch. \& Loeske, Basile et al. (2012) have shown that the appearance of these traits was metal-specific. For metals such as $\mathrm{Pb}$ and $\mathrm{Cd}$, dose-dependence was also observed, while the other two metals tested $(\mathrm{Cu}$ and $\mathrm{Zn})$ showed similar effects at all concentrations. The dose-de- 
pendent effect of $\mathrm{Cd}$ on the cell structure of bryophytes was also confirmed in the study by Carginale et al. (2004), where it led to the changes in the appearance of the membranes of the different organelles (chloroplasts and mitochondria). Besides these changes, the presence of cytoplasmic vesicles, multivesicular bodies, electron dense bodies and lipid droplets was also observed in the cytoplasm of heavy metalstressed bryophytes (Basile et al. 2009, Basile et al. 2012). In the liverwort Lunularia cruciata (L.) Dumort. treated with Cd, Degola et al. (2014) also found numerous small vacuoles containing electron-dense precipitates, which were absent in the control plants. The additional analysis showed that $\mathrm{Cd}$ and sulphur co-localized in these vacuoles indicating an important role of sulphates in the sequestration of intracellular heavy metals.

Along with the ultrastructural changes, heavy metals may also disrupt various metabolic processes and lead to physiological stress in bryophyte cells (Shakya et al. 2008, Sun et al. 2010). These negative effects could be explained by the high affinity of heavy metals for sulfhydryl groups in various proteins, which can lead to inhibition of the enzyme activity (Boquete et al. 2014) or to conformational modifications of the proteins. The alternations in different cell processes could also be a result of the displacement and thus deficiency of an essential element by a specific heavy metal (Zengin and Munzuroglu 2005). The chlorophyll content is an often-used parameter for assessment of the physiological status and biological activity (photosynthetic capacity) of plants (Tremper et al. 2004, Zengin and Munzuroglu 2005, Rau et al. 2007). However, there have not been many studies investigating the relationship between the presence of different heavy metals in bryophytes and the chlorophyll concentration. Additionally, comparable results are limited to laboratory experiments (Varela et al. 2013). Nevertheless, most of these studies have revealed the reduction in total chlorophyll content as a specific response to heavy metal stress, though the degree of it may vary between the species and the metals tested (Choudhury and Panda 2005, Shakya et al. 2008, Sun et al. 2009). In the study of Tremper et al. (2004) on Rhytidiadelphus squarrosus, of the three metals investigated $(\mathrm{Cu}, \mathrm{Zn}$, and $\mathrm{Pb})$ only copper caused a significant decline in the total chlorophyll. The dominant effect of copper and the smallest influence of $\mathrm{Zn}$ on this physiological parameter was also confirmed by Shakya et al. (2008) using the mosses, Thuidium delicatulum (Hedw.) Schimp. and T. sparsifolium (Mitt.) A. Jaeger, and the leafy liverwort, Ptychanthus striatus (Lehm. et Lindenb.) Nees. Additionally, in all three species under heavy metal stress, the amount of chlorophyll b was greater than that of the chlorophyll a, indicating that in these bryophytes heavy metals could induce the conversion of chlorophyll-a to chlorophyll-b (Shakya et al. 2008). Another study, involving he moss Hypnum plumaeforme Wilson, showed that $\mathrm{Pb}$ and $\mathrm{Ni}$, single or combined, at higher concentrations, can also lead to a strong decline in total chlorophyll concentration (Sun et al. 2009). The highly negative effect of $\mathrm{Pb}$ on total chlorophyll content was also demonstrated in the moss Taxithelium nepalense (Schwaegr.)
Broth. (Choudhury and Panda 2005). Additionally, Rother et al. (2006) demonstrated that $\mathrm{Cd}$ too can have a negative effect on chlorophyll content and lead to subsequent loss of vitality in the tested Physcomitrella patens (Hedw.) Bruch \& Schimp. The decline in total chlorophyll content in all the investigated bryophytes under heavy metal stress could be a result of the heavy metal interference with chlorophyll synthesis either through the direct inhibition of an enzymatic step or by inducing the deficiency of an essential nutrient (Zengin and Munzuroglu 2005). The differences in the reduction of chlorophyll content under various heavy metals could be explained by the different uptake and action mechanisms for these metals (Bruns et al. 2001; Shakya et al. 2008).

Since nitrogen is an essential component of amino acids, it has been hypothesised that heavy metals may disturb the biochemical and physiological processes in plant cells through the alteration of the nitrogen metabolism (Sutter et al. 2002). The exposure of the moss Fontinalis antipyretica to increasing concentrations of $\mathrm{Cd}, \mathrm{Pb}$ and $\mathrm{Zn}$ led to a concentration-dependent decrease of nitrogen incorporation into amino acids, and also to an additional concentration-related inhibition of protein biosynthesis. From these observations it can be inferred that the effects were independently influenced by heavy metals at different phases of nitrogen assimilation. The initial reduction of nitrogen incorporation into amino acids may be a consequence of the lowered nitrogen uptake due to the plasma membrane damage, while the discrepancies between the amino acid amounts and the protein abundance may be a result of a concentration-dependent inhibition of protein biosynthesis (Sutter et al. 2002). The influence of heavy metals on nitrogen metabolism in bryophytes was also confirmed by Panda and Choudhury (2005), who found that under $\mathrm{Cr}, \mathrm{Zn}$ or $\mathrm{Cu}$ stress, nitrate reductase of Polytrichum commune Hedw. was inhibited.

Apart from the direct alteration of biological structures and processes in plant cells, heavy metals can also induce reactive oxygen species like hydrogen peroxide $\left(\mathrm{H}_{2} \mathrm{O}_{2}\right)$, superoxide radicals $\left(\mathrm{O}_{2}{ }^{-}\right)$, and hydroxyl radicals $\left(\mathrm{OH}^{-}\right)$that could react with lipids, proteins, pigments and nucleic acid, resulting in lipid peroxidation, membrane damage or enzyme inactivation (Choudhury and Panda 2005, Panda and Choudhury 2005). In the moss Hypnum plumaeforme exposed to increasing concentrations of $\mathrm{Pb}$ and $\mathrm{Ni}$, single or combined, a dose-dependent increase of two ROS species, $\mathrm{H}_{2} \mathrm{O}_{2}$ and $\mathrm{O}_{2}^{--}$was observed. The increase of the free radicals was more pronounced when the two metals were applied together, indicating the synergistic effect on ROS production and accumulation (Sun et al. 2009, Sun et al. 2010). The study of Choudhury and Panda (2005) of the moss Taxithelium nepalense revealed a similar trend of ROS accumulation under $\mathrm{Pb}$ and $\mathrm{Cr}$. Additionally, the increase of $\mathrm{H}_{2} \mathrm{O}_{2}$ and $\mathrm{O}_{2}{ }^{-}$in the moss cells was demonstrated to be dependent on the duration of the metal treatment. Further, the effect of these heavy metals on lipid peroxidation and membrane distortion through the generation of ROS was investigated by analysing malondialdehyde (MDA), a cytotoxic product of lipid peroxidation (Choudhury and Panda 2005, Sun et 
al. 2009). The increase in MDA content in bryophytes was observed in relation to all metals tested in these two studies, as well as in the study of Panda and Choudhury (2005), who investigated the effects of $\mathrm{Cu}, \mathrm{Zn}$, and $\mathrm{Cr}$ on the moss Polytrichum commune. This confirms that heavy metals lead to oxidative stress in bryophytes, which can result in lipid peroxidation, MDA accumulation and consequently the loss of membrane integrity and cell damage (Sun et al. 2009). Additionally, the observation that $\mathrm{H}_{2} \mathrm{O}_{2}$ and MDA accumulated under all metal treatments (Choudhury and Panda 2005, Panda and Choudhury 2005, Sun et al. 2009) proportionally with the increase in duration and concentration of the treatment, implies that these parameters could be used as markers of oxidative stress induced by heavy metals, even when there are no changes in the appearance of the bryophytes (Sun et al. 2009).

\section{Mechanisms of bryophyte resistance to heavy metal pollution}

The toxic effects of heavy metals in bryophyte cells are predominately caused by the intracellular fraction while the metals outside the cells do not have immediate effects on cellular metabolism (Fernández et al. 2006, Shakya et al. 2008, Basile et al. 2012). Thus, the strategies used by bryophytes in response to heavy metal stress may include both the avoidance and the tolerance of this type of abiotic stress. Avoidance includes all the processes preventing the entrance of the heavy metals into the protoplast (Krzesłowska et al. 2013), and in that sense, the cell wall plays a crucial role (Basile et al. 2009). Modification of any of the characteristics influencing its retention and cation exchange capacities, or the activity of metal transporters in plasma membrane could lead to exclusion of heavy metals (Boquete et al. 2014). For example, differences in the cell wall chemical composition between the mosses and liverworts or in different species in a group, could explain the differences in the uptake of different metals and thus the differences in their sensitivity to these pollutants observed in Shakya et al. (2008). The significance of the cell wall in avoiding heavy metal stress in bryophytes has also been demonstrated by Wells et al. (1995). They have shown that the degree of tolerance to cadmium may be influenced by the cell wall binding of different non-toxic cations naturally occurring in the cells or the environment, which then can create unfavourable conditions for the binding of heavy metals around the plasma membrane and prevent their entrance into the cytoplasm.

In contrast to avoidance mechanisms, tolerance to heavy metal stress involves neutralisation of the metals or their toxic effects as well as translocation of these metals from the cytoplasm to compartments such as the vacuole and cell wall. Chelating of heavy metals is one of the strategies involved in maintaining heavy metal homoeostasis and metal detoxification inside the plant cells (Krzesłowska et al. 2013). In the process of intracellular heavy metal chelation in plants, low molecular weight thiols such as glutathione (GSH) and cysteine play the crucial role. GSH is a major transport and stor- age form of reduced sulphur and it may be directly involved in the binding of the heavy metals or indirectly as a substrate for the synthesis of the phytochelatins (PCs) that have a particularly high affinity for some heavy metals. The formed complexes between the heavy metal ions and PCs can then be transported into the vacuole, decreasing the concentration of metals in the cytoplasm and protecting the plants from their deleterious effects (Yadav 2010). These mechanisms also operate in bryophytes as has been demonstrated by Carginale et al. (2004) and Degola et al. (2014) in studies on the liverwort Lunularia cruciata exposed to cadmium stress. The results have shown that $\mathrm{Cd}$ is accumulated in the vacuoles of the Cd-stressed liverwort and that this is accompanied by an increase of sulphur concentration in this organelle. More importantly, it has also been found that most of the intracellular $\mathrm{Cd}$ is bound to the thiol-rich compounds of similar weight such as phytochelatins, indicating that, as in other plants, these compounds may constitute the principal mechanism for heavy metal sequestration. Further, Degola et al. (2014) have unambiguously confirmed that the compounds found in the L. cruciata are phytochelatins and that some of them (such as PC2) may constantly be present in bryophyte cells managing the homeostasis of the micronutrients. However, testing the effects of different heavy metals on the induction of phytochelatin synthesis, and comparing the results of this study with those from a study of Arabidopsis thaliana (L.) Heynh., led to the conclusion that bryophyte PCs and their synthases have a narrower function, involved only in the regulation of the Fe/Zn homeostasis and detoxification of Cd. Conversely, phytochelatin synthases and phytochelatins of $A$. thaliana are more responsive and involved in the effective detoxification of many different heavy metals, indicating that other mechanisms may have greater significance for the detoxification of these elements in bryophytes. Thus, mechanisms other than complexation of heavy metals with phytochelatins have a more important part to play in bryophyte detoxification of heavy metals. This has been additionally confirmed by Bruns et al. (2001). During their study performed on the moss F. antipyretica and 19 other bryophyte species, no phytochelatins could be detected in any of the tested species regardless of the metal and concentration applied. During that time, however, an increase of GSH content, primarily under Cd treatment, could be observed. The findings of this study and the studies performed by Carginale et al. (2004) and Degola et al. (2014) showed that intracellular Cd is primarily stored in the vacuoles of bryophyte cells. Here, high amounts of S and P were also observed, which led to the conclusion that one of the dominant mechanisms of bryophyte tolerance to heavy metals, at least to $\mathrm{Cd}$, is the formation of cytoplasmatic GSH/Cd complexes and their subsequent transport into vacuoles, where they can be degraded and the $\mathrm{Cd}$ accumulated as phosphate.

Apart from the need of bryophytes to neutralise or remove heavy metals from the cells to avoid harmful effects on cellular structures and processes, they also have to possess an antioxidative system to deal with the overproduction of reactive oxygen species caused by heavy metals. This system 
comprises numerous enzymes and compounds of low molecular weight (Zengin and Munzuroglu 2005). SOD is one of the most important enzymes in the protection of plant cells against oxidative stress since it transforms superoxide radicals into less destructive $\mathrm{H}_{2} \mathrm{O}_{2}$ that can further be removed by peroxidase (POD), catalase (CAT), or ascorbate peroxidase (APX). Additionally, low molecular weight compounds such as ascorbic acid (AsA), glutathione, non-protein thiol, cysteine, proline and others could directly interact and detoxify these reactive species (Sun et al. 2009). Sun et al. $(2009,2010)$ treated the moss H. plumaeforme with different concentrations of $\mathrm{Pb}$ and $\mathrm{Ni}$, singly or combined, to investigate the activity of the ROS scavenging system under heavy metal stress in bryophytes. They discovered that the predominant enzyme involved in the bryophyte protection against the oxidative stress induced by heavy metals was POD, with its activity being dose-dependent on the concentrations of the applied metals. Additionally, a synergistic effect of these metals with POD activity was observed. The activity of other enzymes (APX and SOD) was only slightly increased, while the catalase activity actually decreased. On the other hand, the accumulation of both of the investigated components of the non-enzymatic antioxidative system (AsA and proline) has been detected, with $\mathrm{Pb}$ and $\mathrm{Ni}$ displaying a synergistic effect on their accumulation. This indicated that both AsA and proline could be important superoxide anion scavengers in bryophyte cells, with a significant role in the reduction of the damage to cell membranes under heavy metal stress. The accumulation of these two low molecular weight substances in response to the stress induced by metals other than $\mathrm{Ni}$ and $\mathrm{Pb}$ has been also observed in other plants, indicating that they could represent significant heavy metal tolerance constituents in other bryophytes (Zengin and Munzuroglu 2005).

It has been hypothesised that the successful survival of different species in polluted environments is a consequence of their high reproductive potential. Thus, the production of large amounts of spores or gemmae could explain the widespread distribution of some bryophytes in the areas with high amounts of heavy metals (Leblanc and Rao 1974). Since the inhibition of sexual reproduction in many bryophytes in a heavy metal-polluted environment has often been detected (Leblanc and Rao 1974, Shaw 1987), vegetative reproduction as an alternative strategy could explain their success in these disturbed sites (Carginale et al. 2004). They showed that the gemma cups from the cadmium-treated gametophytes of $L$. cruciata produced normal gemmae that germinated at the same rate as those from the controls when transplanted into fresh medium. Vegetative reproduction is one of the important bryophyte strategies under the conditions of heavy metal stress. This is emphasized by the fact that in these plants, high amounts of cadmium were found in the gemma cups, while only minute quantities reached the gemmae themselves. In general, the importance of the reproductive potential for bryophyte survival in heavy metalpolluted environments has also been confirmed by Basile et al. (2001). They demonstrated that gametophyte and sporo- phyte tissues of bryophytes accumulate heavy metals differently, with gametophytes containing much higher concentrations of metals. Further analysis showed that the placenta between them is responsible for this unequal distribution. It disturbs the apoplastic continuity between the two generations and sequesters toxic metals or toxic concentrations of micronutrient metals, preventing their accumulation in the sporogenous tissue and spores. This way, cells are protected during meiosis from the harmful effects of heavy metals in polluted environments.

\section{Conclusions}

Heavy metals are extremely toxic and may cause many alterations in the physiology and morphology of bryophytes, modifying the way they integrate, retain and release these pollutants. Such metals also induce different exclusion mechanisms in bryophytes that reduce heavy metal toxicity by preventing the entry of these elements into the tissues (Wolterbeek 2002, Boquete et al. 2014). Thus, the accuracy and reliability of information obtained using these plants as biomonitors depend on the understanding of the mechanisms, factors and bryophyte species responses (Fig.1) that



Fig. 1. Main factors influencing bryophyte heavy metal content. 
can influence the uptake and the linearity of the relationship between dose and tissue content (Berg et al. 1995, Berg and Steinnes 1997). Though there are studies about the effects of heavy metals on bryophyte physiological parameters, there are only a few examining the consequences of these changes to dose-response relations (Wolterbeek 2002). Additionally, detection of the heavy metal dose-dependent effects and physiological responses in bryophytes at a cellular level could result in the establishment of markers, which could be used for bioindication or biomonitoring of heavy metal pollution in the environment (Rau et al. 2007, Sun et al. 2010). The significance of exploring the heavy metal effects in bryophytes goes beyond their use in environmental studies, since it could also give the insights into the evolu-

\section{References}

Agarwal, S. K., 2009: Heavy metal pollution (Vol. 4). APH publishing, New Delhi.

Basile, A., Cogoni, A. E., Bassi, P., Fabrizi, E., Sorbo, S., Giordano, S., Cobianchi, R. C., 2001: Accumulation of $\mathrm{Pb}$ and $\mathrm{Zn}$ in gametophytes and sporophytes of the moss Funaria hygrometrica (Funariales). Annals of Botany 87, 537-543.

Basile, A., Sorbo, S., Aprile, G., Conte, B., Cobianchi, R.C., Pisani, T., Loppi S., 2009: Heavy metal deposition in the Italian "triangle of death" determined with the moss Scorpiurum circinatum. Environmental Pollution 157, 2255-2260.

Basile, A., Sorbo, S., Pisani, T., Paoli, L., Munzi, S., Loppi S., 2012: Bioacumulation and ultrastructural effects of $\mathrm{Cd}, \mathrm{Cu}, \mathrm{Pb}$ and $\mathrm{Zn}$ in the moss Scorpiurum circinatum (Brid.) Fleisch. \& Loeske. Environmental Pollution 166, 208-211.

Berg T., Røyset O., Steinnes E., 1995: Moss (Hylocomium splendens) used as biomonitor of atmospheric trace element deposition: estimation of uptake efficiencies. Atmospheric Environment 29, 353-360.

Berg, T., Steinnes E., 1997: Use of mosses (Hylocomium splendens and Pleuroziumschreberi) as biomonitors of heavy metal deposition: from relative to absolute deposition values. Environmental Pollution 98, 61-71.

Boquete, M. T., Bermúdez-Crespo, J., Aboal, J. R., Carballeira, A., Fernández, J. Á., 2014: Assessing the effects of heavy metal contamination on the proteome of the moss Pseudoscleropodium purum cross-transplanted between different areas. Environmental Science and Pollution Research 21, 2191-2200.

Bruns, I., Sutter, K., Menge, S., Neumann, D., Krauss, G. J., 2001: Cadmium lets increase the glutathione pool in bryophytes. Journal of Plant Physiology 158, 79-89.

Canivet, L., Dubot, P., Garcon, G., Denayer, F. O., 2015: Effects of engineered iron nanoparticles on the bryophyte Physcomitrella patens (Hedw.) Bruch \& Schimp., after foliar exposure. Ecotoxicology and Environmental Safety 113, 499-505.

Carginale, V., Sorbo, S., Capasso, C., Trinchella, F., Cafiero, G., Basile, A., 2004: Accumulation, localisation, and toxic effects of cadmium in the liverwort Lunularia cruciata. Protoplasma 223, 53-61.

Castello, M., 2007: A comparison between two moss species used as transplants for airborne trace element biomonitoring in NE Italy. Environmental Monitoring and Assessment 133, 267-276.

Chakrabortty, S., Paratkar, G. T., 2006: Biomonitoring of trace element air pollution using mosses. Aerosol and Air Quality Research 6, 247-258. tion of plant defence mechanisms to this type of pollution (Degola et al. 2014).

Thus, bryophyte species are different from each other in relation to heavy metal stresses. The great disadvantage in biomonitoring studies is inadequate collection of the same species (often mixed with other species, different age, state of health, hydration) as well as the presence of xenic organisms and other, abiotic, factors that can significantly complicate comparisons of the results achieved. Also, it can be expected that different genotypes of the same species can also react differently to heavy metals. However, further studies in controlled conditions of axenic cultures are urgently needed to better our understanding relationship between bryophytes and heavy metals.

Choudhury, S., Panda S. K., 2005: Toxic effects, oxidative stress and ultrastructural changes in moss Taxithelium nepalense (Schwaegr.) Broth. under chromium and lead phytotoxicity. Water, Air, Soil Pollution 167, 73-90.

Claveri, B., Morhain, E., Mouvet C., 1994: A methodology for the assessment of accidental copper pollution using the aquatic moss Rhynchostegium riparioides. Chemosphere 28, 20012010.

Couto, J. A., Fernández, J. A., Aboal, J. R., Carballeira A., 2004: Active biomonitoring of element uptake with terrestrial mosses: a comparison of bulk and dry deposition. Science of the Total Environment 324, 211-222.

Čeburnis, D., Valiulis, D., 1999: Investigation of absolute metal uptake efficiency from precipitation in moss. Science of the Total Environment 226, 247-253.

Degola, F., De Benedictis, M., Petraglia, A., Massimi, A., Fattorini, L., Sorbo, S., Basile, A., di Toppi L. S., 2014: A Cd/Fe/Znresponsive phytochelatin synthase is constitutively present in the ancient liverwort Lunularia cruciata (L.) Dumort. Plant and Cell Physiology 55, 1884-1891.

Fernández, J. A., Vazquez, M. D., Lopez, J., Carballeira A., 2006: Modelling the extra and intracellular uptake and discharge of heavy metals in Fontinalis antipyretica transplanted along a heavy metal and $\mathrm{pH}$ contamination gradient. Environmental Pollution 139, 21-31.

Fernández, J. Á., Pérez-Llamazares, A., Carballeira, A., Aboal J. R., 2013: Temporal variability of metal uptake in different cell compartments in mosses. Water, Air, Soil Pollution 224, 1-9.

González, A. G., Pokrovsky, O. S., 2014: Metal adsorption on mosses: toward a universal adsorption model. Journal of Colloid and Interface Science 415, 169-178.

Järup, L., 2003: Hazards of heavy metal contamination. British Medical Bulletin 68, 167-182.

Kelly, M. G., Girton, C., Whitton B. A., 1987: Use of moss-bags for monitoring heavy metals in rivers. Water Research 21, 1429-1435.

Klos, A., Czora, M., Rajfur, M., Wacławek M., 2012: Mechanisms for translocation of heavy metals from soil to epigeal mosses. Water, Air, Soil Pollution 223, 1829-1836.

Koz B., Cevik U., 2014: Lead adsorption capacity of some moss species used for heavy metal analysis. Ecological Indicators 36, 491-494.

Krzesłowska, M., 2011: The cell wall in plant cell response to trace metals: polysaccharide remodeling and its role in defense strategy. Acta Physiologiae Plantarum 33, 35-51. 
Krzesłowska, M., Rabeda, I., Lewandowski, M., Samardakiewicz, S., Basinska, A., Napieralska, A., Mellerowicz, E.J., Woznyl, A., 2013: $\mathrm{Pb}$ induces plant cell wall modifications - in particular - the increase of pectins able to bind metal ions level. E3S Web of Conferences 1, 26008.

Leblanc, F., Rao D. N., 1974: A review of the literature on bryophytes with respect to air pollution. Bulletin de la Société Botanique de France 121(supl.2), 237-255.

Lee Jr, R. E., Von Lehmden, D. J., 1973: Trace metal pollution in the environment. Journal of the Air Pollution Control Association 23, 853-857.

Little, P., Martin, M. H., 1974: Biological monitoring of heavy metal pollution. Environmental Pollution 6, 1-19.

Maevskaya, S. M., Kardash, A. R., Demkiv, O. T., 2001: Absorption of cadmium and lead ions by gametophyte of the moss Plagiomnium undulatum. Russian Journal of Plant Physiology $48,820-824$.

Markert, B., Weckert, V., 1989: Use of Polytrichum formosum (moss) as a passive biomonitor for heavy metal pollution (cadmium, copper, lead and zinc). Science of the Total Environment 86, 289-294.

Martin, M. H., Coughtrey P. J, 1982: Biological monitoring of heavy metal pollution: land and air. Applied Science, London.

Nagajyoti, P. C., Lee, K. D., Sreekanth, T. V. M., 2010: Heavy metals, occurrence and toxicity for plants: a review. Environmental Chemistry Letters 8, 199-216.

Nickrent, D. L., Parkinson, C. L., Palmer, J. D., Duff R. J., 2000: Multigene phylogeny of land plants with special reference to bryophytes and the earliest land plants. Molecular Biology and Evolution 17, 1885-1895.

Nieboer, E., Richardson, D. H., 1980: The replacement of the nondescript term 'heavy metals' by a biologically and chemically significant classification of metal ions. Environmental Pollution Series B, Chemical and Physical 1, 3-26.

Onianwa, P. C., 2001: Monitoring atmospheric metal pollution: a review of the use of mosses as indicators. Environmental Monitoring and Assessment 71, 13-50.

Panda, S. K., Choudhury, S., 2005: Changes in nitrate reductase activity and oxidative stress response in the moss Polytrichum commune subjected to chromium, copper and zinc phytotoxicity. Brazilian Journal of Plant Physiology 17, 191-197.

Pérez-Llamazares, A., Aboal, J. R., Carballeira, A., Fernández, J. A., 2011: Cellular location of $\mathrm{K}, \mathrm{Na}, \mathrm{Cd}$ and $\mathrm{Zn}$ in the moss Pseudoscleropodium purum in an extensive survey. Science of the Total Environment 409, 1198-1204.

Rau, S., Miersch, J., Neumann, D., Weber, E., Krauss, G. J., 2007: Biochemical responses of the aquatic moss Fontinalis antipyretica to $\mathrm{Cd}, \mathrm{Cu}, \mathrm{Pb}$ and $\mathrm{Zn}$ determined by chlorophyll fluorescence and protein levels. Environmental and Experimental Botany 59, 299-306.

Reski, R., 1998: Development, genetics and molecular biology of mosses. Botanica Acta 111, 1-15.

Rother, M., Krauss, G.J., Grass, G., Wesenberg, D., 2006: Sulphate assimilation under $\mathrm{Cd} 2+$ stress in Physcomitrella patens-combined transcript, enzyme and metabolite profiling. Plant, Cell and Environment 29, 1801-1811.

Rühling, Å., Tyler, G., 1970: Sorption and retention of heavy metals in the woodland moss Hylocomium splendens (Hedw.) Br. et Sch. Oikos 21, 92-97.

Sabovljević, M., Skudnik, M., Vujičić, M., Pantović, J., Nikolić, N., Jeran, Z., Batič, F., Sabovljević, A., 2014: Rain simulation with heavy metal deposition: effects of exposure duration and lead concentration on survival and development of the moss Hypnum cupressiforme. 6th Slovenian symposium on plant biology with international participation, Hoce by Maribor, Book of Abstracts, 30 .
Salemaa, M., Derome, J., Helmisaari, H. S., Nieminen, T., VanhaMajamaa, I., 2004: Element accumulation in boreal bryophytes, lichens and vascular plants exposed to heavy metal and sulphur deposition in Finland. Science of the Total Environment 324, 141-160.

Sassmann, S., Wernitznig, S., Lichtscheidl, I. K., Lang, I., 2010: Comparing copper resistance in two bryophytes: Mielichhoferia elongata Hornsch. versus Physcomitrella patens Hedw. Protoplasma 246, 119-123.

Schröder, W., Holy, M., Pesch, R., Harmens, H., Ilyin, I., Steinnes, E., Alber, R., Aleksiayenak, Y., Blum, O., Coşkun, M., Dam, M., 2010: Are cadmium, lead and mercury concentrations in mosses across Europe primarily determined by atmospheric deposition of these metals? Journal of Soils and Sediments 10, 1572-1584.

Shakya, K., Chettri, M. K., Sawidis, T., 2008: Impact of heavy metals (copper, zinc, and lead) on the chlorophyll content of some mosses. Archives of Environmental Contamination and Toxicology 54, 412-421.

Shaw, J., 1987: Evolution of heavy metal tolerance in bryophytes. II. An ecological and experimental investigation of the" copper moss, Scopelophila cataractae (Pottiaceae). American Journal of Botany 74, 813-821.

Shaw, J., Beer, S. C., Lutz, J., 1989: Potential for the evolution of heavy metal tolerance in Bryum argenteum, a moss. I. Variation within and among populations. Bryologist 92, 73-80.

Shaw, J., Renzaglia, K., 2004: Phylogeny and diversification of bryophytes. American Journal of Botany 91, 1557-1581.

Shaw, A. J., Szövényi, P., Shaw, B., 2011: Bryophyte diversity and evolution: windows into the early evolution of land plants. American Journal of Botany 98, 352-369.

Singh, R., Gautam, N., Mishra, A., Gupta, R., 2011: Heavy metals and living systems: an overview. Indian Journal of Pharmacology 43, 246-253.

Soudzilovskaia, N. A., Cornelissen, J. H., During, H. J., van Longtestijn, R. S., Lang, S. I., Aerts, R., 2010: Similar cation exchange capacities among bryophyte species refute a presumed mechanism of peatland acidification. Ecology 91, 2716-2726.

Strotbek, C., Krinninger, S., Frank, W., 2013: The moss Physcomitrella patens: methods and tools from cultivation to targeted analysis of gene function. International Journal of Developmental Biology 57, 553-564.

Sun, S. Q., He, M., Cao, T., Zhang, Y. C., Han, W., 2009: Response mechanisms of antioxidants in bryophyte (Hypnum plumaeforme) under the stress of single or combined $\mathrm{Pb}$ and/or $\mathrm{Ni}$. Environmental Monitoring and Assessment 149, 291-302.

Sun, S. Q., He, M., Cao, T., Yusuyin, Y., Han, W., Li, J. L., 2010: Antioxidative responses related to $\mathrm{H} 2 \mathrm{O} 2$ depletion in Hypnum plumaeforme under the combined stress induced by $\mathrm{Pb}$ and Ni. Environmental Monitoring and Assessment 163, 303-312.

Sutter, K., Jung, K., Krauss, G. J., 2002: Effects of heavy metals on the nitrogen metabolism of the aquatic moss Fontinalis antipyretica L. ex Hedw. Environmental Science and Pollution Research 9, 417-421.

Tipping, E., Vincent, C. D., Lawlor, A. J., Lofts, S., 2008: Metal accumulation by stream bryophytes, related to chemical speciation. Environmental Pollution 156, 936-943.

Tremper, A. H., Agneta, M., Burton, S., Higgs, D. E., 2004: Field and laboratory exposures of two moss species to low level metal pollution. Journal of Atmospheric Chemistry 49, 111-120.

Varela, Z., Roiloa, S. R., Fernández, J. A., Retuerto, R., Carballeira, A., Aboal J. R., 2013: Physiological and growth responses of transplants of the moss Pseudoscleropodium purum to atmospheric pollutants. Water, Air \& Soil Pollution 224, 1-10.

Vazquez, M. D., Lopez, J., Carballeira, A., 1999: Uptake of heavy metals to the extracellular and intracellular compartments in 
three species of aquatic bryophyte. Ecotoxicology and Environmental Safety 44, 12-24.

Vukojević, V., Sabovljević, A., Sabovljević M., 2004: Effect of ferri(III)citrate and potassium hexacyanoferrate(III) on growth of the moss Bryum argenteum Hedw in vitro. Archives of Biological Sciences 56, 75-78.

Wells, J. M., Brown, D. H., 1987: Factors affecting the kinetics of intra-and extracellular cadmium uptake by the moss Rhytidiadelphus squarrosus. New Phytologist 105, 123-137.

Wells, J. M., Brown, D. H., 1990: Ionic control of intracellular and extracellular Cd uptake by the moss Rhytidiadelphus squarrosus (Hedw.) Warnst. New Phytologist 116, 541-553.

Wells, J. M., Brown, D. H., Beckett, R. P., 1995: Kinetic analysis of Cd uptake in Cd-tolerant and intolerant populations of the moss Rhytidiadelphus squarrosus (Hedw.) Warnst and the lichen Peltigera membranacea (Ach.) Nyl. New phytologist $129,477-486$.

Wolterbeek, B., 2002: Biomonitoring of trace element air pollution: principles, possibilities and perspectives. Environmental Pollution 120, 11-21.
Yadav, S. K., 2010: Heavy metals toxicity in plants: an overview on the role of glutathione and phytochelatins in heavy metal stress tolerance of plants. South African Journal of Botany 76, 167-179.

Zechmeister, H. G., Dirnböck, T., Hülber, K., Mirtl M., 2007: Assessing airborne pollution effects on bryophytes-lessons learned through long-term integrated monitoring in Austria. Environmental Pollution 147, 696-705.

Zechmeister, H. G., Hohenwallner, D., Riss, A., Hanus-Illnar, A., 2003: Variations in heavy metal concentrations in the moss species Abietinella abietina (Hedw.) Fleisch. according to sampling time, within site variability and increase in biomass. Science of the Total Environment 301, 55-65.

Zengin, F. K., Munzuroglu, O., 2005: Effects of some heavy metals on content of chlorophyll, proline and some antioxidant chemicals in bean (Phaseolus vulgaris L.) seedlings. Acta Biologica Cracoviensia Series Botanica 47, 157-164.

Zvereva, E. L., Kozlov, M. V., 2011: Impacts of industrial polluters on bryophytes: a meta-analysis of observational studies. Water, Air \& Soil Pollution 218, 573-586. 